Article

\title{
School Culture and Digital Technologies: Educational Practices at Universities within the Context of the COVID-19 Pandemic
}

\author{
Noé Abraham González-Nieto *D, Caridad García-Hernández and Margarita Espinosa-Meneses
}

check for

updates

Citation: González-Nieto, N.A.; García-Hernández, C.; EspinosaMeneses, M. School Culture and Digital Technologies: Educational Practices at Universities within the Context of the COVID-19 Pandemic. Future Internet 2021, 13, 246. https:// doi.org/10.3390/fi13100246

Academic Editors: Wolf-Tilo Balke and Georgios Kambourakis

Received: 21 July 2021

Accepted: 16 September 2021

Published: 24 September 2021

Publisher's Note: MDPI stays neutral with regard to jurisdictional claims in published maps and institutional affiliations.

Copyright: (c) 2021 by the authors. Licensee MDPI, Basel, Switzerland. This article is an open access article distributed under the terms and conditions of the Creative Commons Attribution (CC BY) license (https:/ / creativecommons.org/licenses/by/ $4.0 /)$.
Division of Communication Sciences and Design, Unidad Cuajimalpa, Universidad Autonoma Metropolitana, Mexico City 05348, Mexico; cgarcia@cua.uam.mx (C.G.-H.); mespinosa@cua.uam.mx (M.E.-M.)

* Correspondence: ngonzalez@cua.uam.mx

Abstract: The pandemic caused by COVID-19 led schools to continue their work by relying on digital technologies. Changes in this matter are observed within three dimensions in the theoretical and conceptual background: (a) the influence of ITC in education, (b) the macrosocial changes in the educational systems and public policy derived from the COVID-19 pandemic, and (c) the impact of the COVID-19 pandemic in higher education and its role for the future. The general objective of this research was to characterize the educational practices executed by the university community (students, professors, and managers) during the emerging remote classes derived from the pandemic at the Universidad Autonoma Metropolitana, Cuajimalpa Campus, a public educational institution in Mexico (through an explanation for each educational actor profile). As specific research objectives, this paper: (a) examines whether the professors and students had enough digital technology to continue with the classes, (b) defines the obstacles they had in the use of said digital technology, and (c) recognizes the existence of innovative educational practices and determines whether stated learning was achieved in educational programs. For this purpose, a mixed methodology was chosen, comprising the application of surveys to students and professors and semi-structured interviews with managers, professors, and students. It was found that there was innovation in the area of resources (material-economic dimension) and in the area of relationships (socio-political dimension), while the discursive dimension (cultural-discursive dimension) was negatively impacted. Based on the above, we conclude that the school culture of the UAM-C is solid and that it has the necessary technological resources to continue with the teaching-learning process. The educational practice was transformed, which resulted in advantages and disadvantages, but despite these situations, most students developed their learning.

Keywords: school culture; digital technology; educational practices; higher education; COVID-19; educational innovation

\section{Introduction}

\subsection{Higher Education and the COVID-19 Pandemic}

In March 2020, several governments around the world declared a state of emergency due to the infectious disease caused by the SARS-CoV-2 virus. The pandemic caused by this virus, also known as COVID-19, led to the closure of educational institutions in different regions of the world. In Latin America, Colombia and Peru were the first countries to declare the cancellation of school activities on March 12. By the seventeenth of that same month, 21.7 million students and 1.3 million professors experienced the closure of their institutions [1].

Higher education has been particularly affected in work carried out by the university: teaching, research, and the dissemination of culture. Paredes-Chacín, Inciarte González, and Walles-Peñaloza [2] foresee in the short term "a retraction of student demand, reflected in a reduction of enrollment as well as an impact on the continuity of research, extension and management processes" (p. 100). There has not only been a change in education but 
also in academic calendars, administrative activities, financial distribution, and the way of teaching. All of these have transformed to allow the continuity of university work.

Mexico has not been left behind in the changes that arose in the higher education sector during the pandemic. The symptoms of vulnerability have been exacerbated for the students who do not have access to electronic devices nor an internet connection. In addition to that, the fact remains that not all students who used to dedicate their full time to study could continue. On the other hand, the training of professors concerning media and digital literacies is still a pending issue since there has not been a complete adaptation to the instructional architectures required for satisfactory distance education. Given all this, it is necessary to consider that "institutions, their leaders and their constituents, will have to develop innovative and effective solutions to improve the learning of their students, and make the best use of digital and face-to-face media" [3] (p. 81).

Several research projects have been held to study the relationship between education, technologies, and the COVID-19 pandemic [4-6]. A group of studies analyzes how pedagogical practices have been transformed with the incorporation of information and communication technologies. Salinas Ibáñez [4] indicates that school culture must consider that both teachers and students are digital citizens living in the knowledge society; because of this reason, institutions must incorporate new strategies to make didactics relevant for all school participants. In this context, not only new practices but new pedagogies have been applied in the pandemic scenario, taking into consideration that places and times have changed for all educational actors: nowadays, students "interact, collaborate, and take ownership of their own learning at their own pace and time" [5] (p. 21), fostering teachers' creativity to enhance students' participations in multiple formats, both synchronously and asynchronously.

Another transformation in the educational arena has been observed with the macrosocial dimension of education: Educational Systems and Departments of Education have changed their principles and paradigms of instruction [7-9]. These pieces of research agree on the need to redefine curriculum, assessment procedures, and political principles to serve a world that is changing at a quick pace. Even the concept of "pandemic pedagogies" [9] as a way to promote a social and educational viewpoint on how teachers, schools, and managers would have to transform their educational practices in order to make schooling relevant in a world where uncertainty in education is the new constant element.

Finally, another cohort of studies points out the need to study the higher education scenario with a prospective view [10-13]. They explore how the teacher role has changed in this new educational context and the competencies that are needed within the profession of education [10]. Furthermore, they point out the need to establish a new crisis-oriented agenda in which educational actors are aware of their role in transforming the school culture in an emergency setting [13]. Finally, some studies that retrieve the pedagogical and qualitative paradigm of the topic talk about the voices that students and general educational actors raise in the middle of this situation: they have opened spaces to obtain life histories of participants from multiple settings to point out that there are two dimensions that are not considered in the new educational models: structural barriers that diminish the right to education (socioeconomic status, social discrimination, and technological divide) and the socioemotional impact that has been caused by the COVID-19 pandemic [12].

In this framework, where higher education seems to need to transform its educational practices from the roots, the general objective of this research was to characterize the educational practices executed by the university community (students, professors, and managers) during the emerging remote classes derived from the pandemic at the Universidad Autonoma Metropolitana, Cuajimalpa Campus, a public educational institution in Mexico (through an explanation for each educational actor profile). As specific research objectives, our paper sought: (a) to know if the professors and students had enough digital technology to continue with the classes, as well as to (b) define the obstacles they had in the use of said digital technology, and to (c) recognize the existence of innovative educational practices and determine whether stated learning was achieved in educational programs. 
We chose the theoretical perspective of Kemmis et al. [14], who state that education is "... the practice through which children, youths and adults are initiated into other practices" (p. 37). Therefore, we describe school culture as a set of practices regulated by discourses and norms in which school agents regulate and participate. This allowed us to analyze how the school culture developed during the emerging remote education.

\subsection{The Case of the Universidad Autonoma Metropolitana in Mexico and Its Contingency Response to the COVID-19 Pandemic}

The Universidad Autonoma Metropolitana (UAM) is a federally funded public higher education institution in Mexico. It is comprised of five campuses: Azcapotzalco, Cuajimalpa, Iztapalapa, Lerma and Xochimilco. Azcapotzalco, Iztapalapa, and Xochimilco were founded in 1973 as a result of substantial changes in higher education carried out by the then president of Mexico, Luis Echeverría Álvarez. It was one of the Mexican Government's responses to the social debt caused by the 1968 movement and the student massacre of October 2 in the "Plaza de las Tres Culturas" in Mexico City. It also sought to provide for the growing enrollment of young people graduating from high school in response to the country's economic development project. UAM's Cuajimalpa Campus was founded in 2006 and the Lerma Campus in 2009.

One of the guiding principles of the founding of UAM Cuajimalpa (UAM-C) was the incorporation of information and communication technologies for education, as well as the humanistic formation of autonomous, critical, and proactive professionals who have values and ethics and are respectful of the environment and cultural diversity. For UAM, the foundation of the Cuajimalpa Campus represented the academic and administrative renewal of the university; the trend to implement digital technologies for education was one of its main tasks.

Currently, UAM Cuajimalpa offers 11 undergraduate programs, 1 specialty, and 4 postgraduate programs (master's and doctorate) in 3 academic divisions: natural sciences and engineering, social sciences and humanities, and communication sciences and design. The latter has a unique academic composition in Mexico: the undergraduate programs it contains are traditionally located in different academic divisions; social sciences (communication sciences), architecture (design), and computer engineering (information technology and systems). Moreover, it also has an interdisciplinary Master's Degree in Information Design, Interaction Systems and Communication Strategies. The focus of this study will be on this specific academic division.

UAM's academic organization is governed by a series of regulations that address each of the university's functions: organizational structure; functioning of collegiate bodies; defense of university rights; planning, budgeting, and recruitment transparency; academic staff; research; students; and studies and conditions for studying. It is also governed by a series of policies such as general policies; cross-cutting policies to eradicate gender-based discrimination and violence; operational policies for teaching; operational policies on compliance, evaluation, and promotion of postgraduate programs and curricula; policies to determine mechanisms for evaluation and promotion of research areas; operational policies on editorial production; and operational policies on liaison and the regulations of the Board of Trustees.

This detailed ordering of each of the university functions has its advantages and disadvantages. On the one hand, all aspects of university life (administrative and academic) are covered, and it stands out as their members act in accordance with university legislations. On the other hand, matters that were not contemplated in the legislation are unlikely to be dealt with or will prove difficult to deal with. Such is the case of the incorporation of new technologies for distance education.

UAM's legislation has been the result of historic tensions between the university as an academic entity and the workers' union, the latter of which had, to a certain extent, hindered the evolution of the university's general activities and the implementation of educational technologies. The university's collective contract considers the functions of all staff that works in the university, both academic and administrative. However, its 
conceptualization is based on the working conditions of the 1970s, when the institution was founded.

The incorporation of educational platforms has been uneven across the five campuses that make up the university. Each campus made its own platform based on the autonomy granted to it by the university legislation, without any direction from the General Rector's Office on the uses and appropriation of digital technology to consider the institution's educational model. This explains the diversity of opinions and proposals on the use of digital technology for education within the UAM, as the legislation states that the teachinglearning process must be face-to-face [15].

Considering the health contingency, the Universidad Autonoma Metropolitana started the Emerging Remote Education Program (PEER in Spanish), which "takes the best of the face-to-face model and enriches it by the incorporation of pedagogic strategies for virtual education" [16] (p. 12). The purpose of the PEER implementation in the UAM was to address a worldwide emergency that would only work during the duration of the confinement [17]. However, its implementation already showed the diversity of technology used by the university community and the different levels of knowledge and management of it.

The advantages and disadvantages of using it have become apparent. Some advantages include: students and professors have developed skills and strategies for academic work, there is continuous work to improve the design of online academic activities, there is learning in the use of technology, university managers continue to improve technological and academic conditions as a whole, and students have been able to continue their school work at home and been able to save resources in transport and food. Some disadvantages include: not all students have access to the technology due to lack of resources, high-cost internet for those who do not have a home installation, the need to go to work, domestic violence, some professors of advanced age that refused to learn how to use digital technology, and others.

The COVID-19 pandemic and the social distancing it forced upon us as humanity has made evident the fundamental issues that the university should address: access to digital technologies for education, the training of students and professors to improve online work, the development of communication skills through digital technologies, the innovation of educational practices that privilege learning, among others. Addressing these issues is part of the educational culture, as the access, use, and appropriation of information and communications technologies (ICTs) will allow students to develop fundamental skills to cope in an increasingly digitized social world. It will also help students work cooperatively in distance scenarios and manage their time between personal, academic, and work-related aspects, which has become a trend that has become more evident in the last year.

\subsection{School Culture in the University Educational Context}

Defining a school is complex, as it implies delving into the description of a social institution which, in a way, is a reflection of the culture that contains it, but at the same time, contains its own actors, practices, rules, objects, relations, and meanings which constitute it as a subculture within each society. Julia [18] speaks of "school culture" as a place in which there are "norms that define the knowledge to be taught and the behavior to be inculcated, as well as the correlative series of practices, constructed within the educational institutions over time" (p. 131). These norms and practices are followed by school agents (professors, students, managers) who act in accordance with the way of thinking of society with what is institutionalized and approved by each cultural group.

Viñao [19] also points out the existence of this school culture, which is materialized through a set of institutionalized aspects such as practices and behaviors, habits and rituals, material objects (function, use, and symbolism), shared meanings, and ideas. Thus, he states that "school culture is the whole of school life: facts and ideas, minds and bodies, objects and behaviors, ways of thinking, saying and doing" (p. 253). In the same sense, Escolano [20] speaks of the existence of a practical culture, an academic culture, and a 
political culture that develop and shape the social institution called school. The practical culture is materialized through school practices (exhibitions, ways of working which correspond to specific theories and times), while academic culture is conformed by a series of knowledge approved for teaching within the school. Finally, the political culture refers to the discourses and norms that turn the school into an organization; it is about regulations and documents that express the school's ideology and serve to maintain control in the school.

As one can observe, these authors coincide in pointing out that school culture is made up of school actors (students, professors, managers) who share meanings and representations of what their role is within that field. These actors know and carry out the practices or activities (exposing, writing, reading, debating, evaluating, etc.) that are considered necessary to achieve their goals (teaching, learning, managing, etc.). They always act within a normative framework that regulates them. Within this dynamic, objects (books, materials, technology, etc.) play not only a symbolic role but are also the very means that make it possible to achieve objectives. All these elements are related, and over the years, they have built the social institution called school.

It should be noted that the appropriation of school culture depends on the cultural capital that the students and professors have acquired through their personal trajectories. Firstly, from family and their approach to knowledge; secondly, from the social circles in which they have lived (friends, classmates, colleagues, etc.); and finally, the experiences and knowledge that resulted from a relationship of the institutional agents, thus, the values, beliefs, and principles of the university are internalized by the actors, in this case by the students. Educational actors (students, teachers, and managers) reproduce the school perspective of the institution in university life and educational practices. According to Bourdieu [21], cultural capital is a determining element for academic success. In public universities, the different social classes tend to be unequally represented, and as such, the distinction in the appropriation of knowledge and of school culture is evident. Similarly, the access, use, and appropriation of digital technologies is a cultural capital that students and professors have incorporated unequally, and it has been a determining factor for their educational development during social distancing and distance education, as we will see below.

The socio-historical construction of school culture explains why it is difficult to transform the dynamics established between students, professors, and managers; it is difficult to change the conception and practices of what the professor's role is in the classroom and, as a consequence, the role the student must assume and their habits and responsibilities in the teaching-learning process. After all, these conceptions have been established and consolidated for decades. In regard to this, Kemmis et al. [14] state that classrooms and schools have remained stable as social forms closer to the nineteenth-century concept of school, where education was thought of as a civilizing purpose and schooling as an instrument of discipline. They point out that this concept is perhaps closer to the present time than the idea of a world with digital technology with globalized cultural, economic, and political imperatives (p. 1), in which the concept of teaching-learning favors the development of cognitive, socio-affective, and communicative knowledge that should govern: a learning process that focuses its attention on the formation of citizens with abilities and knowledge that enables them to transform their environment.

Faced with this panorama, it is worth asking: how does one change this type of education, this type of school culture that has survived in many classrooms and seems to conserve a concept of learning that is more related to an object that can be transferred from the professor to the student? Kemmis et al. [14] point out that in order to transform these educational conceptions and practices, it is necessary to influence the school culture itself. For example, educational practices cannot be replaced without changing the conception of what it is to teach and learn. Thus, he states that human beings relate to each other in intersubjective spaces, within which there is a common language; material-economic agreements that operate in a space and a time (for example, a home, a museum, a classroom, 
a virtual classroom) and that restrict the way in which an activity can be carried out; and socio-political agreements that regulate the way in which the members of a group, family, or digital community relate to each other. These three elements (discourse, material-economic, and sociopolitical) are the ones that must be innovated to truly change educational practices. After all, these three elements which are always present in school and social practices, somehow regulate culture itself.

This proposal by Kemmis et al. [14] corresponds to the architecture of practices, in which education is defined as the practice in which a student is initiated into other practices. Thus, the concept of education would be given from the learning of these first three practices:

- The material-economic agreement: this first practice relates to the resources that make it possible for activities to take place; it develops the dimension of a given space-time. It enables and restricts the practices; it comprises resources and spaces (such as a classroom, a playground, school furniture, virtual classroom), digital technology, etc. This dimension makes educational acts and events possible.

- The cultural-discursive agreement: this practice is the dimension of language and meanings; therefore, it also regulates other practices such as the fact of expressing oneself in a certain way in a certain place of the fact of being able to share the same specialized language of a discipline, which requires the speakers know it. This dimension makes conversation possible.

- The socio-political agreement: this kind of practice regulates relations between people and interactions with objects, in a family, in a virtual classroom, and in a school. This dimension makes social relations possible.

These agreements can be found in any social space and can reproduce or transform practices, such as, for example, in school culture. It is these three elements applied in school culture and in the context of emergency remote education resulting from the COVID-19 pandemic on which we base the analysis of the data described below.

\subsection{Research from Educational Practice as a Catalyst for Pedagogical Transformation}

As mentioned in the previous section, school transformation requires starting from school culture itself, considering the actors that have a direct impact on it: students and educational managers (among others). As such, in order to achieve pedagogical transformation, it is necessary to carry out research that starts from the experience of the actors in their daily practices through projects that are directed by the community itself. The "from within" vision allows the research to take a situated and significant role for the participants who are a part of it. Additionally, they are given the opportunity to systematically question their actions and educational practices that are implemented in the daily life of the institution.

When educational stakeholders are positioned critically and in relation to their roles in school culture, they acquire the social and political agency that enables them to innovate and transform educational practices and teaching and learning objectives. Moreover, through this vision, "they control their own agenda for change and develop their capacity to transform practices in their own sites" [14] (p. 179). Thus, research acquires a dual purpose: it helps to critically reflect on educational practice based on personal perspective and in relation to others, and it fosters a process of continuous evaluation that leads to consistent innovation in the activities that take place in the activities carried out in the dimension of conversation (language), acts, and relationships.

Education renewal is possible when its actors are committed to researching, critically reflecting on, and continuously evaluating their practices. Thus, this is work that happens on an individual and collective level and accounts for how school culture is shaped by decisions that are made daily and that can be modified. Therefore, the capacity for action and transformation depends on those who commit themselves to "look back on pedagogical events, analyze them, make judgements about them and transform their teaching" [14] (p. 203) based on the characteristics of social realities and evidence from research. As such, 
this project is part of the transformative approach that sees the action of educational actors as the key to promoting deep and lasting pedagogical transformations.

\section{Materials and Methods}

One of the current concerns for investigators of social sciences is to carry out the fieldwork with the protagonists of the investigation from a horizontal perspective. That is to say, to communicate with them in order to understand, from their perspective-as much as possible - their daily lives, their needs, and interests, their conceptions of what surrounds them. This was the principle we tried to follow with the social actors during each of the phases of the research.

\subsection{Focus of the Methodological Approach}

For the design of instruments that allowed us to collect information, our goal was to explore school culture of the UAM-C with its actors, practices, and specific activities, with its institutional regulations and organization with its work through the PEER and its decision making. For this purpose, we opted for mixed research $[22,23]$ in a case-oriented project [24], in which both quantitative and qualitative paradigms were considered. It is important to mention that for this work, the gathering of information was implemented through a survey whose objective was to generate a profile of the actors of education in the UAM Cuajimalpa exclusively since it was a priority to highlight the qualitative aspects of the research.

The selected instruments for this project were:

(a) Quantitative surveys (Professors' / Managers' version and Students' version): the quantitative methodology was based on surveys addressing the following dimensions:

(1) Access and use of digital technologies: access to internet, quality of access to internet, number of hours dedicated to academic activities, and technological platforms that were commonly used.

(2) Educational interactions: types of learning activities (synchronous and asynchronous) that were applied, benefits/obstacles when using internet, communication procedures among actors, and support of technological platforms to the learning processes.

(3) Prospective view on the topic: university's capacity to transform its procedures and serve its population with innovative practices and further actions that are needed to improve the educational experience during the COVID-19 pandemic.

(4) Socioemotional experience: socioemotional states (anguish, sadness, uncertainty, calm, overwhelmed, sleep pattern alteration, fear, anger, tension, no change) and their relationship with the educational experience during the COVID-19 pandemic.

The instrument was administered via Google Forms and then analyzed using Excel functions. Before applying the instrument, a validation process was held by a group of experts in education and innovation. Finally, as the universe was known, the finite universe formula was used to calculate the sample. With the parameters of $95 \%$ of confidence level and a margin of error of $5 \%$, the sample size consisted of 249 surveys.

(b) Semi-structured interviews and Focus Groups: in the implementation of the qualitative methodology, the same dimensions of the survey were addressed, but the advantages and disadvantages of remote working were further explored as well as the assessment of the achievement of the teaching objectives. The combination of quantitative and qualitative techniques provided valuable information to recreate the representation that the university community has about: (1) access to digital and internet technologies; the use of ICT for teaching-learning process by students and professors, the type of technology used, teaching-learning strategies; and (2) educational interactions, the decisionmaking of managers, the performance of professors in their educational work, the role of students in their learning (theoretical and procedural contents, attitudes, and values), time organization, self-study, discipline, punctuality, and cooperation. Data analysis was completed with the use of Nvivo 12, and validation processes were held with a group of experts in the field. 
The number and type of participants in the research instruments are displayed in Table 1.

Table 1. Survey participation.

\begin{tabular}{ccc}
\hline Instrument & Educational Actors & Number of Participants \\
\hline \multirow{2}{*}{ Quantitative surveys } & Students & 254 \\
\cline { 2 - 3 } Semi-structured interviews & Professors & 46 \\
\cline { 2 - 3 } & Students & 01 \\
\cline { 2 - 3 } & Professors & 06 \\
\hline \multirow{2}{*}{ Focus groups } & Managers & 06 \\
& Students obtaining a Bachelor's Degree in \\
& Communication Sciences & 06 \\
& Students obtaining a Bachelor's Degree in \\
Information Systems and Technology & 06 \\
\cline { 2 - 3 } & $\begin{array}{c}\text { Students obtaining a Master's Degree in Design, } \\
\text { Information and Communication }\end{array}$ & 06 \\
\hline
\end{tabular}

The analysis and interpretation of the data were carried out in two phases. First, the findings of each of the approaches (quantitative and qualitative) were analyzed separately. Subsequently, regular meetings were held in which researchers socialized the data from both research paradigms to give an integral perspective of the data.

With regard to the quantitative information, graphs and statistics were generated to show the trends of the educational actors in the context of the Emerging Remote Education Program (PEER in Spanish), while the qualitative information was subjected to a process of open and theoretical coding in phases [25] that allowed for the information to be categorized into descriptive families that list the characteristics of the implemented educational practices by students, professors, and managers. Finally, the data were compared based on a triangulation process of the different instrument types (survey, interviews, and focus groups) and research approaches (quantitative and qualitative) to ensure the validity of the study.

\subsection{Educational Actors}

In this study, we focus on the analysis of school culture in one of the three academic divisions of the campus where three undergraduate study programs coincide (Communication Sciences, Design, and Information Technologies and Systems) and in a postgraduate degree (Master's Degree in Design, Information and Communication). We consider the case of the Division of Communication Sciences and Design (DCCD in Spanish) of the UAM-C to be distinct from what happened to the university as a whole because this division was dedicated to facilitating access to technology to the entire community. The words and actions that took place, in this case, make up a system of relationships about what people think, feel, and act in a situation of uncertainty such as the COVID-19 pandemic. The data presented here specifically correspond to the DCCD of the UAM-C.

In terms of the educational actors who participated as part of the survey, we have the following roles:

- Professors: the professors at this university are hired under the research professor scheme, in which half of their time is dedicated to education, and the other half is dedicated to research. At UAM-C, $89.9 \%$ of professors are full-time, and $60.6 \%$ have doctoral studies.

- Managers: the managers of the institution are professors elected by the divisional and academic councils. Their term as managers in the university lasts 4 years. 
- Students: the students of the UAM-C are characterized by belonging to middle and medium-low economic sectors. A total of $38.5 \%$ of them come from within Mexico, $50.4 \%$ have studied in public schools, and $45 \%$ are women and $55 \%$ are men.

\subsection{Research Procedures}

From the first approaches of the UAM-C community, we obtained the information that allowed us to draw a diagnosis about how technology-mediated education was developing as a result of the sudden decision to move all undergraduate and postgraduate courses to "online mode". In order to achieve this, professors made use of the technological platform they knew as Ubicua (UAM-C platform based on Moodle) or Classroom. Other professors decided to communicate via email, Whatsapp, or videoconferencing software (Zoom, Meet, or similar). The methodological structure was as evidenced in Figure 1:

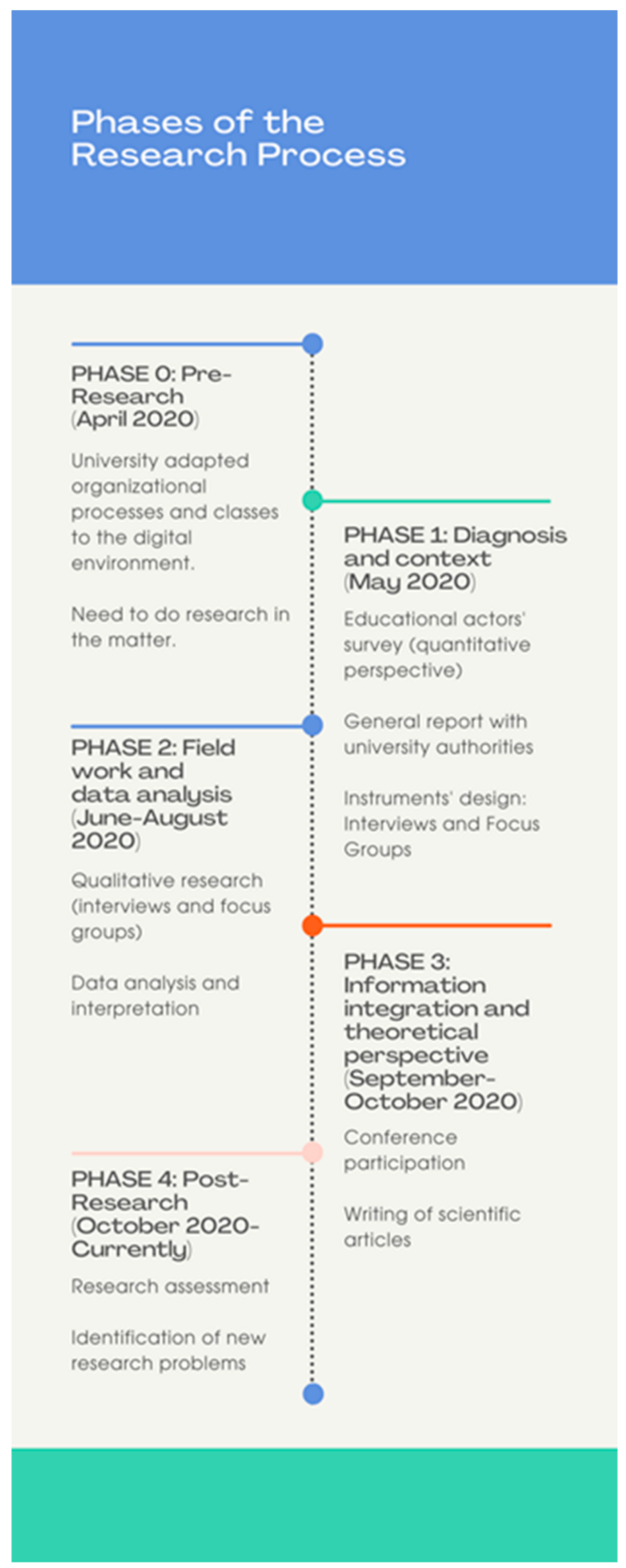

Figure 1. Research process. 


\title{
3. Results
}

As stated in the general research objective, in the next section, we characterize the educational practices shown by the university community during the pandemic. This is completed with the identification of common characteristics in the profiles of the participants who were part of the study: students, professors, and managers.

\subsection{Quantitative Perspective Results}

The data collected made it possible to show, on the one hand, the availability of digital technology to professors and students as well as the way in which they used it (dimension of resources, economic material agreement) and let us see the ways of relating through language and through the technologies themselves.

\subsubsection{Students}

The first category that was recorded was access to digital technologies. All students surveyed (254) had a digital device that allowed them to access the internet. A total of $97 \%$ of students reported having internet service at home.

When it came to the use of technology for classes, students stated that they preferably used two educational platforms (33\% Moodle; $18 \%$ Classroom) for school activities and email $(13 \%)$ to communicate with professors asynchronously, whilst Zoom (29\%) was mostly used to communicate synchronously. Figure 2 shows the main technological tools used in remote learning.

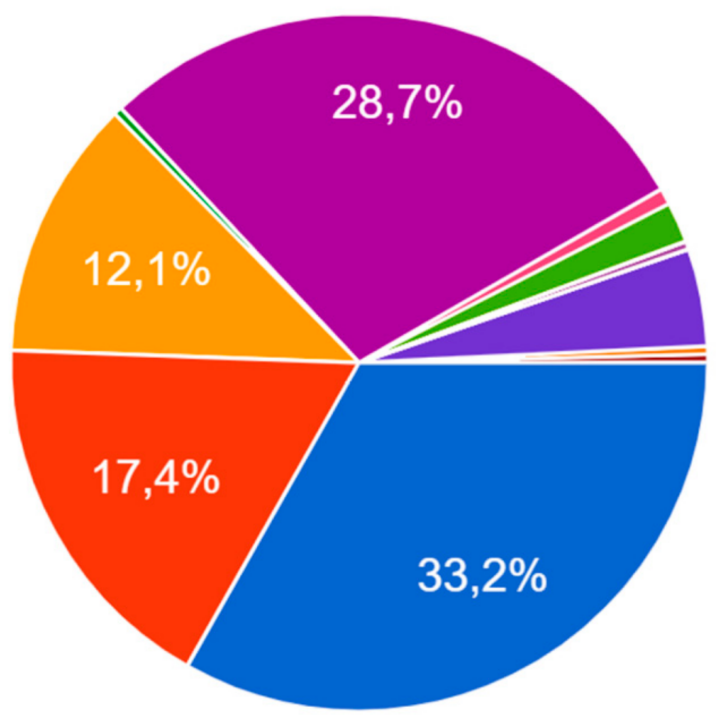

\author{
Ubicua platform \\ Google Classroom \\ Email \\ Free software \\ Zoom \\ Meet \\ Virtual Library \\ Whatsapp
}

Figure 2. Technological tools in remote learning (students).

Despite the fact that students tend to use all types of technology, 13\% stated that they did not know how to use educational platforms (see Figure 2).

\subsubsection{Professors and Managers}

A total of $46(60 \%)$ of professors surveyed declared that they had enough digital technology (computers and internet access) to continue the teaching and learning process from their own homes. However, $24 \%$ of them stated that they did not know how to use the educational platform used in the university (Moodle and Google Classroom).

According to Figure 2, the most used technology as a means of educational interaction was a combination of the following technological platforms: Google Classroom (24\%), Moodle (26\%), and Zoom (22\%). Email was also recorded as a means of communication used by $9 \%$ of professors (see Figure 3). 


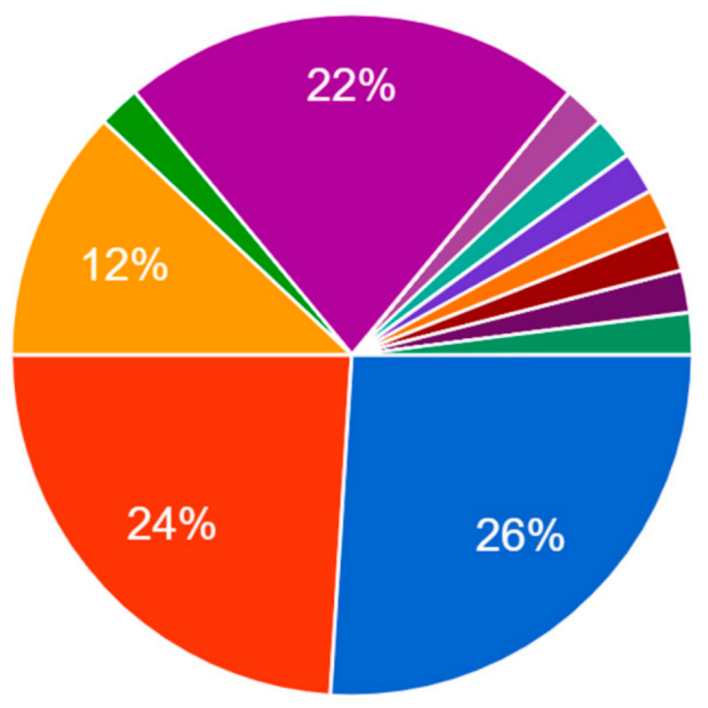

\section{Ubicua platform \\ Google Classroom \\ Email \\ Free software \\ Zoom \\ Meet \\ Virtual Library \\ Whatsapp}

Figure 3. Technological tools in remote learning (professors).

Professors used digital technology for various activities (respondents were able to choose more than one answer in this question). Three educational practices stood out synchronously: explanations through Zoom (64\%), chatting with students $(34 \%)$, and $21 \%$ debates (through Zoom, Meet) among group participants.

Asynchronously, technology was used mainly for sending and receiving information (84\%) and for submitting assignments (84\%). Discussion forums were used by $40 \%$ of participants, and online tests were used by $18 \%$.

Digital technology was also used by professors to create their own teaching materials. A total of $56 \%$ of participants stated that they used technology to design materials, $53 \%$ stated they used it to search for information, and $40 \%$ used it to produce and edit videos. All recorded uses of technology by professors are presented in Figure 4.

Discussion forums

Send and receive information Edit and produce videos Design of materials Search information

Podcasts

Wikis

Online exams

Sending homework

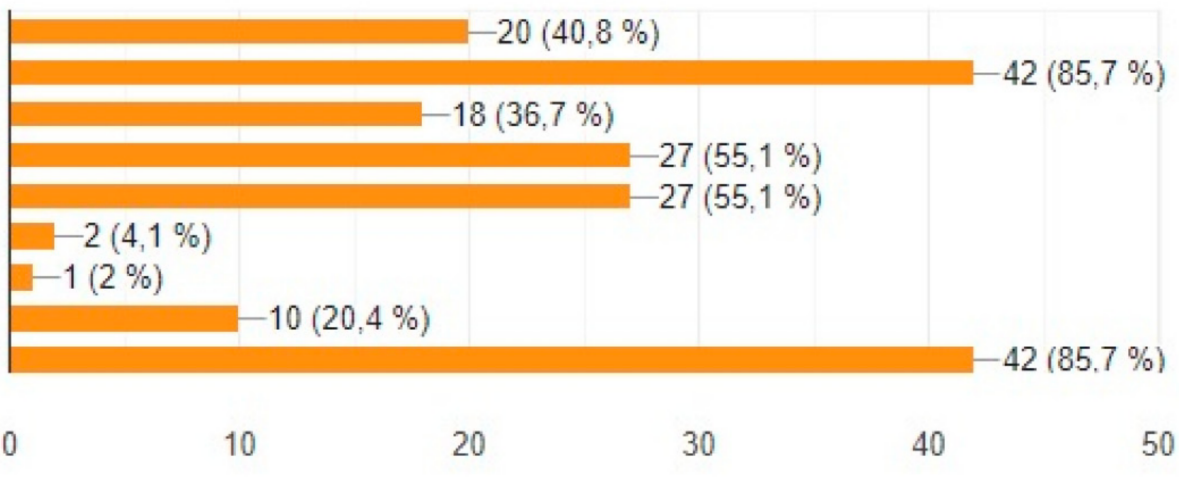

Figure 4. Uses of technology by professors.

Although all professors used digital technology to continue with remote classes, a significant percentage of them (24\%) stated that they did not know how to use the educational platforms (learning management systems). That is to say, that there was no appropriation of educational technology among this percentage of respondents. In the same vein, $58 \%$ of professors indicated that they required short courses on specific topics to solve their doubts about technology, and 31\% asked for online help to explain specific doubts. This suggests that the appropriation of educational technologies is at different levels, according to the roles and experiences of the academic actors. 
The school culture at the UAM-C was transformed by the pandemic. From the students' perspective, the educational objective was achieved by the majority, although this knowledge was in varying degrees of appropriation, as shown in Table 2.

Table 2. Levels of appropriation in learning.

\begin{tabular}{|c|c|c|c|c|c|}
\hline Types of Learning & Very Good & Good & Average & Bad & There Was No Learning \\
\hline $\begin{array}{c}\text { Do you consider that your } \\
\text { theoretical learning during the } \\
\text { quarter was... }\end{array}$ & $10 \%$ & $36 \%$ & $37 \%$ & $15 \%$ & $2 \%$ \\
\hline $\begin{array}{l}\text { Do you consider that your } \\
\text { procedural learning } \\
\text { (programming, editing, mockups, } \\
\text { taking a picture, prototyping, } \\
\text { researching ... ) was ... }\end{array}$ & $8 \%$ & $35 \%$ & $42 \%$ & $10 \%$ & $5 \%$ \\
\hline $\begin{array}{l}\text { Do you consider that the learning } \\
\text { in attitudes and values } \\
\text { (organization of time, self-study, } \\
\text { discipline, punctuality, } \\
\text { cooperation, etc.) was ... }\end{array}$ & $12 \%$ & $47 \%$ & $32 \%$ & $8 \%$ & $1 \%$ \\
\hline
\end{tabular}

\subsection{Qualitative Perspective Results}

This section presents the results according to the profile of the educational actors involved (students, professors, and managers), and their answers were obtained in the semi-structured interviews.

For the coding process, the theoretical framework of Kemmis et al. (2013) was considered to define the three qualitative categories from which the analyzed material would be classified: (1) material-economic agreement (educational acts and deeds), (2) culturaldiscursive agreement (conversations-perspective of language), and (3) socio-political agreement (social relations). Subsequently, qualitative manifestations were identified within each category in order to analyze how the implementation of each of the abovementioned agreements was carried out. As such, strengths (positive perspective) and weaknesses (negative perspective) were identified with respect to the educational practices exercised by the participants, which are detailed in Tables 3-5.

(a) The material-economic agreement (educational acts and deeds) 
Table 3. Codes in the material-economic agreement.

\begin{tabular}{|c|c|c|}
\hline Perspective/Evaluation & Code & Description \\
\hline \multirow{5}{*}{ Strengths (positive) } & Competences of the distance learner & $\begin{array}{c}\text { Developing knowledge, skills, and attitudes for } \\
\text { distance learning }\end{array}$ \\
\hline & Class structure & $\begin{array}{l}\text { Class structure and didactic sequence that makes the } \\
\text { teaching-learning process possible }\end{array}$ \\
\hline & Technological platforms & $\begin{array}{l}\text { Practices in technological platforms that make the } \\
\text { teaching-learning process possible }\end{array}$ \\
\hline & Redefining processes & Positive assessment of new roles within the university \\
\hline & Role of the university & $\begin{array}{l}\text { Positive assessment of the university's role in the } \\
\text { context of the pandemic }\end{array}$ \\
\hline \multirow{6}{*}{ Weaknesses (negative) } & Socio-digital divide & $\begin{array}{l}\text { Significant differences of educational actors in accessing } \\
\text { information and communication technologies }\end{array}$ \\
\hline & University bureaucracy & $\begin{array}{l}\text { Administrative processes that hinder the university's } \\
\text { substantive functions }\end{array}$ \\
\hline & Competences of the distance learner & $\begin{array}{l}\text { Lack of knowledge, skills, and attitudes to } \\
\text { distance learning }\end{array}$ \\
\hline & Class structure & $\begin{array}{l}\text { Class structure and didactic sequencing that hinder the } \\
\text { teaching-learning process }\end{array}$ \\
\hline & Technological platforms & $\begin{array}{l}\text { Practices on technology platforms that hinder the } \\
\text { teaching-learning process }\end{array}$ \\
\hline & Environmental problems & $\begin{array}{l}\text { Environmental conditions that hinder the } \\
\text { teaching-learning process }\end{array}$ \\
\hline
\end{tabular}

(b) The cultural-discursive agreement (conversations-language perspective)

Table 4. Codes in the cultural-discursive agreement.

\begin{tabular}{ccc}
\hline Perspective/Evaluation & Code & Description \\
\hline Strength (positive) & Communication platforms & $\begin{array}{c}\text { Effective communication practices in information } \\
\text { technology and communication-mediated education }\end{array}$ \\
\hline Weakness (negative) & Communication noise & $\begin{array}{c}\text { Undesirable factors hindering communication in } \\
\text { ITC-mediated education }\end{array}$ \\
\hline
\end{tabular}

(c) The socio-political agreement (social relations)

Table 5. Codes in the socio-political agreement.

\begin{tabular}{|c|c|c|}
\hline Perspective/Evaluation & Code & Description \\
\hline \multirow{2}{*}{ Strengths (positive) } & Empathy & $\begin{array}{c}\text { Acknowledgment of the characteristics, needs, and } \\
\text { problems of other educational actors }\end{array}$ \\
\hline & Teaching role & $\begin{array}{l}\text { Professor relationships with students and managers that } \\
\text { enable the teaching-learning process }\end{array}$ \\
\hline \multirow{3}{*}{ Weaknesses (negative) } & Personal effects & $\begin{array}{l}\text { Social relations inside and outside the university that } \\
\text { hinder the teaching-learning process }\end{array}$ \\
\hline & Teaching role & $\begin{array}{l}\text { Professor relationships with pupils and students that } \\
\text { hinder the teaching-learning process }\end{array}$ \\
\hline & Collegial work & $\begin{array}{l}\text { Lack of collegial work between educational actors to } \\
\text { achieve common objectives }\end{array}$ \\
\hline
\end{tabular}




\subsection{Overall Results}

The overall results from the qualitative inquiry are displayed in Table 6 . This chart outlines the number of times that each category appeared in the coding process.

Table 6. Overall results.

\begin{tabular}{|c|c|c|c|}
\hline \multicolumn{4}{|c|}{ Material-Economic Agreement } \\
\hline \multirow{2}{*}{ Perspective/Evaluation } & \multicolumn{3}{|c|}{ Educational actors } \\
\hline & Students & Professors & Managers \\
\hline Strength (Positive) & 53 & 37 & 39 \\
\hline Weakness (Negative) & 61 & 13 & 24 \\
\hline \multicolumn{4}{|c|}{ Cultural-Discursive Agreement } \\
\hline \multirow[t]{2}{*}{ Perspective/Evaluation } & \multicolumn{3}{|c|}{ Educational actors } \\
\hline & Students & Professors & Managers \\
\hline Strength (Positive) & 18 & 16 & 13 \\
\hline Weakness (Negative) & 13 & 2 & 6 \\
\hline \multicolumn{4}{|c|}{ Socio-Political Agreement } \\
\hline \multirow[t]{2}{*}{ Perspective/Evaluation } & \multicolumn{3}{|c|}{ Educational actors } \\
\hline & Students & Professors & Managers \\
\hline Strength (Positive) & 33 & 29 & 32 \\
\hline Weakness (Negative) & 25 & 6 & 16 \\
\hline
\end{tabular}

\subsubsection{Students}

In terms of economic-material agreement, it was found that the technology represented both a possibility or a limitation for the promotion of an effective teaching and learning process. In the focus group, one student stated that when the learning management system allowed the interaction with the professor and classmates, the educational process was more meaningful: "For example, having to enter links to blogs, to surveys ... As you mentioned, what we did last class that we had to do surveys and questionnaires. I think they are a very effective tool because you can learn from other classmates, and you can share your learning" (focus group).

Another aspect to highlight was the importance of the diversity of learning materials that promoted learning according to the needs of each student: "I think that the professor knew how to manage the subject and gave us not only lectures but also ways to make the class more dynamic since we would watch videos and films on how it was related to the computer and its history" (focus group).

Finally, the students highlighted the relevance of synchronous videoconferences as a complement to the activities on the platform: "As for Zoom, the truth is that I liked Zoom better. It has several tools that are actually really cool since the administration professor made virtual groups" (focus group).

Contrary to the analysis of good practice in promoting learning, students stated that not all the strategies used by their professors were effective. A first observation consisted in the lack of competence development for practically oriented subjects: "the other optional subject which was containers and packages. So, like to make boxes, design them a little, propose and think of a complete project that in the end should have been pretty practical but the problem was that that subject stopped being practical and become part theoretical of lectures and analysis" (interview). An additional factor was centered on the monotony of educational materials and the lack of meaningful evaluation: "I think we did lack that feedback from the professors that only sent a PDF. As in, they sent a PDF each week and you don't get that feedback from them" (interview). 
When it came to the cultural-discursive agreement, students participated in communication processes with other educational actors (professors and students) to promote academic achievement and a sense of belonging. The first element that students highlighted was the organization and systematization of the professors to carry out their daily communication: "what I found very useful and I was very grateful about was how much the professors only used one way to communicate" (focus group). Additionally, the sense of belonging and empathy was built from effective communication processes between professors and students, as stated by a student in the focus group: "I also have to recognize that by having good communication, they (professors) have had the freedom to understand the different complications that may exist in the student body; one never knows what may be happening to another classmate's family"(focus group).

Although there were good communication practices, there were also drawbacks to effective communication. In this case, there were connectivity problems that hindered the teaching-learning process, as one student mentioned when talking about their experience in videoconferences: "I had trouble understanding and would many of the Zoom meetings we had could cut off at $40 \mathrm{~min}$. I think I told the professor about it and in truth I dunno know if the change was made because the session that was gonna implement them was the one when the earthquake happened" (focus group). On other occasions, the problem focused on the lack of teaching, specifically on the students' lack of understanding of a specialized language and the professors not giving them enough explanations: "It seems to me that this form of working is not correct, all that are lectures because sometimes we don't understand some terms. I'm from the technology department, and I don't know management terms". Moreover, there was an absence of feedback on the work presented by the students: "Going back to (the issue of) feedback, if I have a question about a class or how to deliver a paper, they will give it. The problem is when I have done that, they don't respond to any of the work I handed in. Like, I literally don't know about how it came out." (Focus group).

Finally, in the socio-political agreement, the meaningful relationships of the actors fostered the construction of communities with motivation for learning. One of the students stated that their educational experience changed thanks to the relationship and didactic structure that the professor implemented with their students since it gave them certainty and confidence: "In my opinion, the one was most successful in this semester was the UEA of human-computer interaction with Professor Samantha. It started from before the term, always gave us the guideline and always gave us a bit of certainty within all the uncertainty" (focus group). Additionally, there was confidence in the students to approach their professors to solve academic and personal problems, as can be seen in this extract from the focus group: "I can't complain much about the communication. I mean, there was communication with my professors because I had a problem with re-enrollment in which all of my subjects disappeared. I contacted them, they told me it was fine, and we resolved it" (focus group).

\subsubsection{Professors}

In the material-economic agreement, it was found that professors renovated their teaching materials and technological platforms to adapt them to the needs observed by the students. A professor commented that they did tests to produce the teaching resources that had an impact on their students' learning: "apart from that, I filmed videos that I uploaded to Ubicua (which) was an ideal solution because I used that in my interactions with the students and in the videos that I uploaded. In my videos I was filming myself, I also shared my screen and my presentations, and I used this thing called Open Board as a sort of whiteboard" (interview). In addition, they combined synchronous and asynchronous communication strategies to improve the students' learning experience and provide continuous feedback: "I thought of doing some sessions together, I mean through Zoom, in videoconference, together with tasks that had to be solved through the week or from one to two weeks and I associated those tasks with a discussion forum for doubts" (interview). 
Finally, given that some subjects made use of specialized software, the professors sought open source solutions so their students could meet their learning objectives: "Open source alternatives allow students to not have to crack the programs, nor have to go and risk their computer's integrity. It's much better for their computer" (interview).

With regard to the weaknesses present in the material-economic agreement, it was found that the professors consider that the students' ability to use educational software is limited: "our communication students have very below-average use of any software, even from other universities. This is concerning, and we need to put more effort in, but it would help. I think that it also has to do that we're not giving the same to the professors in the laboratories" (interview). In addition, the impossibility of technology platforms to follow up on elements of human communication continues to be a pending issue. For example, a professor said they felt limited in the resources they had to know how their students were progressing in the videoconferences: "In the case of the UEAs without videoconferences, we don't know what their doubts are or what are the most troublesome parts of the content. In class, one can see their faces and know: they can understand me, they don't understand me, half of the class is lost, right?" (Interview).

By considering the cultural-discursive agreement, professors constructed a pedagogical discourse that enables professor-student interactions for the promotion of learning, both on platforms that foster synchronous and asynchronous communication. This allowed for the implementation of a constructivist educational model that accounts for the interactions between the different actors in the classroom: "there were very good discussions ... I do believe in constructivism, I think we gave them the space to develop, and I think that they were able to make their own knowledge, it's not a slogan nor anything like that" (interview). In addition, different synchronous and asynchronous platforms were used to achieve these learning objectives: "the discussion forums are a way to adapt to the student's time because many of them go to the campus and then go to work" (interview). Finally, they offered many times and spaces to articulate this pedagogical discourse: "My class is Monday, Wednesday, and Friday. I connect on Monday and Wednesday without a doubt, and on Friday, I only ask those who have doubts to log in and want advice" (interview).

Finally, in the socio-political agreement, the professors strengthened their relationships in different dimensions to promote an effective teaching and learning process: professorstudent (motivation and empathy) and professor-professor (collegiate work and continuous improvement). In the first instance, the professors recognized that it is not possible for all the students to have their cameras on, so they were flexible in this sense: "from the start, I told them that whoever could have their camera on, to turn it on. If they couldn't because of their living situation or it wasn't allowed at their home or they were not in an emotionally sound enough to open their intimate space for us, to not open it. I am not going to force anyone" (interview). By being more empathetic, the professors have also provided a specific evaluation and feedback process to guide the learning activities: "let's see if they didn't understand this in the course, then how can I make them understand ... So, the time of evaluation and the effort of evaluation have changed a lot" (interview).

The pandemic made professors aware of their role in promoting the health and emotional stability of their students, as one of the professors interviewed commented: "the situation made me rethink my students as human beings and become aware of their situation and try to put myself in their shows to not exaggerate in rigor" (interview). Another of the professors highlighted that the modifications to their classroom strategies have allowed more students to achieve the expected learning: "I have a student who lost power, who lost internet, I do not know the details, but she wrote me that she was very lucky because she went to an internet café to do her homework that she didn't need the software since WordPress works as a single space that was modeled in the cloud. She was able to solve her problems in that internet café" (interview).

One of the weaknesses is the spaces for collegial work. A professor stated that they felt that they "navigated alone" since they did not know how their colleagues were working, which is why he said: "I think it is even a request that I would ask is to know what my 
colleagues are doing, how they are doing it. To know how they are working and know what they are doing in their classes. Because I have no idea: I do not have any idea on how they are doing it" (interview).

\subsubsection{Managers}

In the material-economic agreement, it was found that the managers collaborated in the collegial construction of documents, guidelines, and practices for the proper implementation of the Emerging Remote Education Program (PEER in Spanish). A first element consisted of sensitizing and training the educational community with respect to the digital resources available, as one of the department directors points out: "It was very intense work because we did not know how to use Zoom. We started to use it, that is to say, we had meetings through Google Meet or Whatsapp, and then we moved to Zoom and started to work on that platform. We had at least a week or 10 days to think intensively about how the university was going to react" (interview). In addition, one of the study coordinators reported having probed out their students and professors about the existence of specialized software licenses for the subjects in order to assess the possibility of providing training and the necessary resources in this regard (both at a cost or free access).

In addition, an assessment was made of the conditions of access to technology by the university population, with the aim of expanding coverage through new technologies. As such, a computer-loaning mechanism through which "students could take a used laptop from the university, sign a letter of responsibility, and return it at the end of the term" (interview). Finally, the managers had to make available to the educational community additional services such as psychological counseling and thanatology in order to support students, professors, and administrative staff to proactively deal with the presence of psychosocial disorders resulting from the pandemic. One of the study coordinators stated the following: "I provided the contacts that have been announced for thanatology, psychology. There is a list of contacts and phone numbers; I think that they are still on the page of UAM Cuajimalpa. I have directly provided these to whoever asked me for it, and I had consistently been publishing it in the group that we have" (interview).

The health contingency also led managers to rethink the functioning and organization of the university in order to innovate in administrative practices that had become outdated. One of the department directors stated the following: "things can be done differently, and we hadn't done them this way because we had no need to do so. For example, on a managerial level, it was clear that committee meetings do not have to be face-to-face" (interview). Additionally, the Director of the Division of Communication Sciences and Design commented that, starting from now, distance education modalities should be considered for any program: "I do believe that it makes more sense and it would be more productive to make the training programs and formation, and even the student equipment to consider the characteristics that we have delimited in the kind of activities that are being proposed for the UEA that work at a distance" (interview).

By considering the cultural-discursive agreement, the managers established linguistic codes to promote communication with educational actors in order to innovate in the university management process. In contrast to what happened when education was carried out face-to-face, now, professors have more possibilities to be in contact and follow up on teaching and research projects, as stated by a study coordinator: "I can say that for the better, I think there is more participation in the meetings. They are more frequent. I consider that we did not meet up as often as we did when we were working face-to-face" (interview). Another research coordinator said that the communication channels with students have expanded: "We used Whatsapp for direct communication, answering doubts, feedback, announcements, etc., as the number one option. There are professors that took their class in a completely asynchronous way in Ubicua: they only saw them at the start and end of the term but were practically every day on Whatsapp answering doubts ... " (interview).

Finally, in the socio-political agreement, the managers generated mechanisms to promote the integration of the community in the achievement of common goals, although 
not in all cases were they satisfactory. The Academic Secretary of the Campus stated that from the beginning of the pandemic, they sought to "provide the professors with certain courses and tools so that they could be more empowered with regard to platforms or certain strategies" (interview). Nevertheless, she commented that she tried to establish collaborative networks with her counterparts in other divisions but was faced with resistance: "I proposed it to them, and they were like ... no, we don't understand you" (interview). In this sense, she reflects on the importance of strengthening relations beyond the professional sphere: "we work every day together, and in truth, we know each other very little. Very little. I think that it is very important because otherwise, how are we going to build a community that not only consists of the academic component? First and foremost, we are people, and speaking of ourselves as people is very difficult, isn't it?" (interview).

\section{Discussion}

This research focused on the analysis of three dimensions that are present in any practice of school culture (material-economic, discursive, and political agreements), which were changed in the context of the confinement caused by the pandemic in the context of digital technologies for education. Additionally, it characterized the educational practices that were executed by the university community of the Universidad Autonoma Metropolitana, Cuajimalpa Campus, in Mexico City.

This research evidenced that professors, students, and managers transformed their educational practices to incorporate technological platforms, new ways of virtual interaction and community formation, and means to achieve learning objectives with the use of multiple tools. As identified by Talavera and Junior [6], the profile of the university has changed as it now needs to incorporate innovative processes and competencies to apply its substantive functions. Furthermore, educational practices during the pandemic have shaped a new way to carry out education and plan educational policies from the needs of the community of the UAM, Cuajimalpa Campus. This finding is supported by Miguel Román, who establishes the new paradigms and functions that the university must consider in this new era: formats of studying (on-site/off-site), teacher preparedness to use technologies in class, university infrastructure, and the student profile [12].

As stated by Salinas Ibáñez [4], information and communication technologies can help to improve the development of the educational process with the use of new platforms. Nevertheless, the case of the public university in Mexico also needs to consider the heterogeneous condition of its population, as it comes from multiple socio-economic settings, and the digital divide is a present problem. Thus, public policy in Mexico must be shaped to help the national educational system to be flexible towards the multiple changes that are present in the contemporary period, as stated by Ordorika [13]. The collaboration among multiple members of the society is key to make these transformations relevant for the whole community.

Drawing from the theoretical background of Kemms et al. [14], we found that the material-economic dimension was the one that changed the most. Despite the pandemic, school culture at UAM-C developed in the digital technology space, mostly through the internet. This was possible by the actions of diverse school actors. The administration provided both professors and students with the necessary resources to sustain educational interactions and lent computers, blackboards, and software licenses so that professors and students could continue their work. Professors designed their courses according to their technological and pedagogical competencies. The pedagogical intervention of some professors was reduced to an exchange of materials via email, while for other professors, the design consisted of the formal creation of a virtual classroom with materials, debates, and activities and complimented their teaching practice through Zoom sessions. This diversity of designs and technological resources resulted in advantages and disadvantages in relation to student learning, as stated by the educational agents. Even though some students had connectivity resources, these were not optimal, as some pointed out constant connection failure and lack of specific software for certain courses. On the same hand, 
there was a constant complaint about the approach to practical learning content (mockups, handling of lights and camera, use of radio booths, workshops, etc.), subjects that were difficult to develop at the virtual level, and whose teaching is still pending.

The discursive dimension was negatively affected. Although the educational actors stated that communication was possible despite the technological inconveniences, the students stated that their doubts were not fully resolved, and above all, there was a complaint about the lack of feedback on the written assignments. We believe that this was due to the excessive work the professors had to perform in preparing materials for the remote classes, the lack of knowledge-in many of them — on how to use the educational platforms, or the fact that feedback practice is usually carried out in an oral way and as such, did not take place in remote classes, and therefore needs to be addressed by the professors.

The sociopolitical dimension saw significant changes. The pandemic was the main factor that changed work policies, which were more flexible. For example, the delivery times of the activities were longer; the students could miss synchronous sessions through Zoom without penalty and had the possibility of watching the class recordings and the videos recorded by the professors explaining the topics, which meant that the information would always be available to the students. This derived from empathetic relationships, driven by the pandemic that everyone was going through. Another significant change was the increase of collegial work among professors; although it was not widespread, there was more work together than in face-to-face classes.

This research and reflection exercise allowed visualizing the importance of having systematization exercises of one's own teaching practice. The authors of this work, apart from working as researchers on the subject in question, are professors who have faced social, educational, and technological challenges of education on a daily basis during the period of confinement. Therefore, carrying out a project of this nature showed how the results of research on one's own practice can bring benefits for innovating teaching and learning strategies in a technology-mediated context.

Considering the perspective of Kemmis et al. [14], the need for new education for a new world is evident. Knowing the context of the UAM-C as a case made visible the strengths and weaknesses of current education systems and is a reminder that education needs a prospective view in order to train its actors in terms of the future for a new student and professor profile [26,27]. As such, the innovations made by the educational actors in their everyday school contexts were the ones that kept the education mediated by digital technologies, and it is from this that the new plans for the future of education must be shaped. The combination of actors and their perspectives will make the transformation in education relevant to present and future challenges.

\section{Conclusions}

Transforming school culture is no simple task; the university is a system that has been consolidated over centuries on the basis of power relations between agents acting inside and outside the institution. Passeron [28] pointed out that the history of culture is equivalent to the history of the way the dominant classes have managed to permeate the social collective, from which derived customs, ways of life, behaviors, attitudes, expressions, and symbols that are reproduced in different scenarios, as is the case of the university.

In the case of the UAM, one can see the institutional organization-with the characteristics mentioned above, with a community of lecturers-researchers, with a trade union that dominates the work environment with an educational model that in the UAM-C is framed in constructivism-are elements that define the use of digital technologies for education. Academic and administrative organizations play a determining role in the use of ICTs as they have been present in the university in laboratories, workshops, and research. However, these have not been able to be consolidated for use in education, despite having an educational platform.

For UAM students, access to digital technologies has not been homogenous and, in some cases, has represented a great challenge due to their economic conditions. In 
the case of professors, the relationship with technologies depended on different reasons (age and their approach to ICT; disinterest to use them for education or preference for face-to-face education). In any case, asymmetric relationships are observed in the academic performance of students and professors, the effect of which is reflected in teaching and learning. This shows that educational institutions are social spaces determined by explicit and hidden curricula, by hierarchical groups according to their skills and knowledge, by dominant and subordinate cultures, and by competing class ideologies caused by unequal power relations $[29,30]$.

Against this backdrop, it can be said that in the Division of Communication Sciences and Design at the Universidad Autonoma Metropolitana, Cuajimalpa Campus, there was indeed innovation in the educational culture during the confinement caused by the COVID19 pandemic: innovation in the creation of new space and time for the teaching-learning process, and innovation in more flexible relationships between school agents, which generally resulted in a positive experience, as most students reported that they achieved learning. However, there are also the disadvantages or debts that have to be overcome to make school culture more effective: better technological equipment and knowledge in the use of technology, better management of didactic knowledge, better skills in time-management and self-study, the establishment of true didactic dialog, and the revision of practical subjects whose teaching can only be completed through face-to-face teaching.

From the methodological perspective, the cross between the theoretical categories on the material-economic agreement, the cultural-discursive agreement, and the sociopolitical agreement, with the dimensions of the profiles of the participants, allowed us to generate a reflection that outlines concrete practices of students, professors, and academic managers on the role that digital technologies play in the context of the university. We highlighted some facts, such as: (a) prior to the COVID-19 pandemic, the educational model was primarily face-to-face, with a classroom conception of a physical space that is closed, with teachers present but without an emotional connection with the students, and (b) the pandemic promoted concrete actions on the migration to a virtual classroom that is heterogeneous, open, interactive, and socio-affective between students and teachers.

The challenges that this implies are the scope of work of academic management towards the medium- and long-term goals which are in line with the UNESCO goals for 2030. This research points out the need to educate all the young people of the world and a significant proportion of adults in digital and informational literacies in order to increase the understanding, communication, and interpretation of a digitized world with a high flow of information.

A lesson of the pandemic and social distancing for the UAM is that online education is here to stay in a university that resisted-for multiple reasons-technological and educational change. Institutional attention focused for decades on the hyper-specialization of teachers, abandoning pedagogy and innovation. The second lesson is that the university community joined forces, learned from experience and shared knowledge, to join the inertia of technology-mediated education.

The limitations of this research included that the focus of the study was to explore the case of a single university and, thus, did not represent the general educational setting. This occurred because of the population that was studied (specific Campus of a Mexican University) and the nature of the research procedures (qualitative with the support of quantitative surveys), which did not look to give general conclusions or statistics that could be applied to any school or university. On the other hand, the period in which this research was held considers April-October 2020; for this reason, further academic results need to be explored to analyze how the COVID-19 pandemic has influenced the educational settings in subsequent months.

Nevertheless, this research can provide a theoretical and conceptual guide on how to incorporate innovations in digital educational practices considering the concept of "culture" as one of the most relevant parts of educational transformation. Furthermore, these findings contribute to the understanding of the Latin American educational background in an era 
where the comprehension of multiple pedagogical contexts is valued. Additionally, if needed, these results must be adapted to the social context of the readers in order to apply the lessons we have identified in the conclusions.

Author Contributions: Conceptualization, M.E.-M. and N.A.G.-N.; methodology, C.G.-H. and N.A.G.-N.; software, N.A.G.-N.; validation, M.E.-M., N.A.G.-N. and C.G.-H.; formal analysis, M.E.M., N.A.G.-N. and C.G.-H.; investigation, M.E.-M., N.A.G.-N. and C.G.-H.; resources, M.E.-M., N.A.G.-N. and C.G.-H.; data curation, N.A.G.-N.; writing-original draft preparation, N.A.G.-N.; writing-review and editing, C.G.-H. and M.E.-M.; visualization, N.A.G.-N.; supervision, C.G.H.; project administration, M.E.-M. All authors have read and agreed to the published version of the manuscript.

Funding: This research received no external funding.

Institutional Review Board Statement: Not applicable.

Data Availability Statement: Not applicable, the study does not report any data.

Conflicts of Interest: The authors declare no conflict of interest.

\section{References}

1. UNESCO. Covid-19 and Higher Education: Today and Tomorrow. 2020. Available online: http://www.iesalc.unesco.org/en/ wp-content/uploads/2020/04/COVID-19-EN-090420-2.pdf (accessed on 1 April 2021).

2. Paredes-Chacín, A.; Inciarte, A.; Walles-Peñaloza, D. Educación superior e investigación en Latinoamérica: Transición al uso de tecnologías digitales por Covid-19. Rev. Cienc. Soc. 2020, XXVI, 98-117.

3. Alcántara Santuario, A. Educación superior y Covid-19: Una perspectiva comparada. In IISUE. Educación y Pandemia. Una Visión Académica; Universidad Nacional Autónoma de México: Mexico City, Mexico, 2020; pp. 75-82. Available online: http: //www.iisue.unam.mx/nosotros/covid/educacion-y-pandemia (accessed on 28 April 2021).

4. Salinas Ibáñez, J. Educación en tiempos de pandemia: Tecnologías digitales en la mejora de los procesos educativos. Innov. Educ. 2020, 22, 17-21. [CrossRef]

5. Ali, W. Online and Remote Learning in Higher Education Institutes: A Necessity in light of COVID-19 Pandemic. High. Educ. Stud. 2020, 10, 16-25. [CrossRef]

6. Talavera, H.; Junior, F. La educación en tiempos de pandemia: Los desafíos de la escuela del siglo XXI. Rev. Arbitr. Cent. Investig. Estud. Gerenc. 2020, 44, 176-187.

7. Daniel, S.J. Education and the COVID-19 pandemic. Prospects 2020, 49, 91-96. [CrossRef] [PubMed]

8. Grande-de-Prado, M.; García-Peñalvo, F.J; Corell Almuzara, A.; Abella-García, V. Evaluación en Educación Superior durante la pandemia de la COVID-19. Campus Virtuales 2020, 10, 49-58.

9. Williamson, B.; Eynon, R.; Potter, J. Pandemic politics, pedagogies and practices: Digital technologies and distance education during the coronavirus emergency. Learn. Media Technol. 2020, 45, 107-114. [CrossRef]

10. Code, J.; Ralph, R.; Forde, K. Pandemic designs for the future: Perspectives of technology education teachers during COVID-19. Inf. Learn. Sci. 2020, 121, 419-431. [CrossRef]

11. Mendoza Castillo, L. Lo que la pandemia nos enseñó sobre la educación a distancia. Rev. Latinoam. Estud. Educ. 2020, L, $343-352$.

12. Miguel Román, J.A. La educación superior en tiempos de pandemia: Una visión desde dentro del proceso formativo. Rev. Latinoam. Estud. Educ. 2020, L, 13-40.

13. Ordorika, I. Pandemia y educación superior. Rev. Educ. Super. 2020, 49, 1-8.

14. Kemmis, S.; Wilkinson, J.; Edwards-Groves, C.; Hardy, I.; Grootenboer, P.; Bristol, L. Changing Practices, Changing Education; Springer: New York, NY, USA, 2014.

15. UAM. Legislación Universitaria. 2021. Available online: http://www.uam.mx/legislacion/LEGISLACION-UAM-ABRIL-2021 /LEGISLACION-UAM-ABRIL-2021-COMPLETO.pdf (accessed on 30 June 2021).

16. Silva-López, R.B.; González-Nieto, N.A.; Cruz-Miguel, E.; Silva-López, M.I.; Hernández Pérez, J.E. Estrategias de enseñanzaaprendizaje y acompañamiento para la educación virtual: PEER en la UAM-Lerma. In Prácticas Educativas de la UAM Lerma: Del Aula Física al Aula Digital; Silva-López, R.B., Hernández-Razo, O.E., García-Garibay, J.M., Eds.; Universidad Autonoma Metropolitana, Unidad Lerma: Mexico City, Mexico, 2020; pp. 10-42.

17. Universidad Autonoma Metropolitana. Programa Emergente de Educación a Distancia. Available online: https://www.uam.mx/ educacionvirtual/uv/peer.html (accessed on 25 March 2021).

18. Julia, D. La cultura escolar como objeto histórico. In Historia de las Universidades Modernas en Hispanoamérica. Métodos y Fuentes; Menegus, M., González, E., Eds.; Centro de Estudios sobre la Universidad: Mexico City, Mexico, 1995.

19. Viñao Frago, A. Historia de la Educación e Historia Cultural: Posibilidades, Problemas, Cuestiones. Revista de Educación. $\mathrm{N}^{\circ} 306$. La Profesión Docente. 1995; pp. 245-269. Available online: https://sede.educacion.gob.es/publiventa/detalle.action?cod=494 (accessed on 25 March 2021). 
20. Escolano Benito, A. La escuela como construcción cultural. El giro etnográfico en la historiografía de la escuela. Espac. Blanco. Rev. Educ. 2008, 18, 131-146. Available online: https:/ / www.redalyc.org/articulo.oa?id=384539800006 (accessed on 27 June 2021).

21. Bourdieu, P. Los Herederos: Los Estudiantes y la Cultura; Siglo XXI: Buenos Aires, Argentina, 2004.

22. Teddlie, C.; Tashakkori, A. Foundations of Mixed Methods Research Integrating Quantitative and Qualitative Approaches in the Social and Behavioral Sciences; Sage: Los Angeles, CA, USA, 2009.

23. Creswell, J.W.; Plano Clark, V.L. Designing and Conducting Mixed Methods Research; Sage: Los Angeles, CA, USA, 2011.

24. Simons, H. El Estudio de Caso: Teoría y Práctica; Morata: Madrid, Spain, 2011.

25. Saldaña, J. The Coding Manual for Qualitative Researchers; Sage: Los Angeles, CA, USA, 2015.

26. Ramírez-Montoya, M.S.; Loaiza-Aguirre, M.I.; Zúñiga-Ojeda, A.; Portuguez-Castro, M. Characterization of the Teaching Profile within the Framework of Education 4.0. Future Internet 2021, 13, 91. [CrossRef]

27. Miller, R. Anticipating the Future: Anticipation in the 21st Century; Routledge-UNESCO: Paris, France, 2019.

28. Passeron, J.C. La teoría de la reproducción social como una teoría del cambio: Una evaluación crítica del concepto de "contradicción interna". Estud. Sociol. 1983, I, 417-442.

29. Beane, M.; Apple, M. Escuelas Democráticas; Morata: Madrid, Spain, 2002.

30. Eggleston, J. Professor Decision-Making in the Classroom: A Collection of Papers; Routledge: London, UK, 2018. 